\title{
Effect of betaine supplementation on cycling sprint performance
}

\author{
J Luke Pryor ${ }^{1 *}$, Stuart AS Craig ${ }^{2}$ and Thomas Swensen ${ }^{3}$
}

\begin{abstract}
Purpose: To examine the effect of betaine supplementation on cycling sprint performance.

Methods: Sixteen recreationally active subjects (7 females and 9 males) completed three sprint tests, each consisting of four $12 \mathrm{sec}$ efforts against a resistance equal to $5.5 \%$ of body weight; efforts were separated by 2.5 min of cycling at zero resistance. Test one established baseline; test two and three were preceded by seven days of daily consumption of $591 \mathrm{ml}$ of a carbohydrate-electrolyte beverage as a placebo or a carbohydrate-electrolyte beverage containing $0.42 \%$ betaine (approximately 2.5 grams of betaine a day); half the beverage was consumed in the morning and the other half in the afternoon. We used a double blind random order cross-over design; there was a 3 wk washout between trials two and three. Average and maximum peak and mean power were analyzed with one-way repeated measures ANOVA and, where indicated, a Student Newman-Keuls.
\end{abstract}

Results: Compared to baseline, betaine ingestion increased average peak power $(6.4 \% ; p<0.001)$, maximum peak power (5.7\%; $p<0.001)$, average mean power (5.4\%; $p=0.004)$, and maximum mean power $(4.4 \% ; p=0.004)$ for all subjects combined. Compared to placebo, betaine ingestion significantly increased average peak power (3.4\%; $p=0.026)$, maximum peak power max (3.8\%; $p=0.007)$, average mean power $(3.3 \% ; p=0.034)$, and maximum mean power (3.5\%; $p=0.011$ ) for all subjects combined. There were no differences between the placebo and baseline trials.

Conclusions: One week of betaine ingestion improved cycling sprint power in recreationally active males and females.

Keywords: Anaerobic power, Ergogenic aid, Creatine, Wingate

\section{Background}

Betaine is a nutrient found in a variety of animals, plants, and microorganisms [1]. It is a component of many foods, with whole grains (e.g., wheat, rye), spinach, shellfish and beets [2] being rich sources. As an organic osmolyte, betaine or trimethyl glycine, protects cells under stress, such as dehydration; it is also a source of methyl groups, via the methionine cycle, in many key biochemical pathways [1]. Betaine, therefore, plays an important role in several aspects of human health and nutrition and studies show that diets high in betaine decrease disease risk [1,3-5].

\footnotetext{
* Correspondence: john.pryor@uconn.edu

'Department of Kinesiology, University of Connecticut, Storrs, CT 06269, U1110, USA

Full list of author information is available at the end of the article
}

In addition to improving health, betaine may also improve sport performance. Since betaine is an osmolyte that protects cells under stress [6,7], initial studies on the potential ergogenicity focused on the acute effects of betaine ingestion on performance in the heat $[8,9]$. In one study, subjects ran in a heated environment $\left(31.1^{\circ} \mathrm{C}\right)$ for 75 minutes at $65 \%$ of $\mathrm{VO}_{2}$ max followed by a performance run at $84 \%$ of $\mathrm{VO}_{2}$ max to volitional exhaustion [8]. Time to exhaustion was 16 to $21 \%$ (32 to $38 \mathrm{sec}$ ) greater when beverages with betaine or betaine and carbohydrate were consumed, respectively, but the changes were statistically insignificant ( $p \geq 0.12$ ). In the other study, subjects completed a 15 min cycling time trial after riding for $2 \mathrm{hr}$ at $60-75 \% \mathrm{VO}_{2} \max$ in the heat [9]; immediately after the time trial, isometric leg strength was also examined. Acute consumption of either a carbohydrate or a betaine and carbohydrate beverage before
C Biomed Central

() 2012 Pryor et al; licensee BioMed Central Ltd. This is an Open Access article distributed under the terms of the Creative Commons Attribution License (http://creativecommons.org/licenses/by/2.0), which permits unrestricted use, distribution, and reproduction in any medium, provided the original work is properly cited. 
the test improved time trial performance by 10 and $14 \%$, respectively, relative to a water control trial; there was no difference between the carbohydrate and carbohydrate and betaine trials. Isometric leg strength, however, was significantly greater after the betaine trials compared to the non-betaine trials.

This latter result catalyzed a series of inquires on the chronic effects of betaine ingestion (2 weeks) on various indices of strength and power $[10,11]$. The assumption being that since betaine is a methyl donor [1], it could theoretically boost creatine stores in the musculature, and therefore, improve strength and power [10]. Chronic betaine ingestion (at least $2.5 \mathrm{~g} \mathrm{~d}^{-1}$ for $14 \mathrm{~d}$ ) significantly improved bench press repetitions, volume load, throw power, isometric bench press force, vertical jump power, isometric squat force, and muscle endurance during a squat exercise [10-12]. Despite enhancing the aforementioned indices of lower extremity strength and power, chronic betaine ingestion did not improve Wingate anaerobic power [10]. The inability of betaine to enhance cycling sprint performance, as measured with the Wingate anaerobic power test, may be related to the duration of the test and the amount of recovery between trials. Perhaps the $30 \mathrm{sec}$ Wingate test and the $5 \mathrm{~min}$ recovery period between trials were too long to fully assess betaine's putative ability to enhance sport specific strength and power, both of which contribute significantly to Wingate performance. A series of shorter work bouts interspersed with shorter periods of active recovery may be a more applicable test of betaine's potential to enhance anaerobic power while cycling. To that end, our purpose was to examine the effect of one week of betaine ingestion on anaerobic power as measured with a series of four, $12 \mathrm{sec}$ work bouts on the cycle ergometer.

\section{Methods}

\section{Subjects}

Sixteen college-aged males $(n=9)$ and females $(n=7)$ volunteered to participate in this study; their mean \pm SD for age, height, and weight were: $19 \pm 0.8 \mathrm{y}, 172 \pm$ $12.0 \mathrm{~cm}$, and $75 \pm 14.9 \mathrm{~kg}$ and morphological data are present in Table 1. All subjects were free of lower body

Table 1 Body Composition

\begin{tabular}{lccc}
\hline Variable & Baseline & Placebo & Betaine \\
\hline Body Weight $(\mathrm{kg})$ & $75.1 \pm 14.9$ & $74.9 \pm 14.9$ & $75.4 \pm 14.9$ \\
Free Fat Mass $(\mathrm{kg})$ & $60.1 \pm 14.6$ & $59.8 \pm 14.6$ & $59.7 \pm 14.5$ \\
Fat Mass $(\mathrm{kg})$ & $15.0 \pm 0.3$ & $15.1 \pm 0.3$ & $15.7 \pm 0.4$ \\
Percent Fat Mass & $20.1 \pm 10.5$ & $20.2 \pm 10.4$ & $20.9 \pm 10.9$ \\
Total Body Water $(\mathrm{kg})$ & $44.0 \pm 10.7$ & $43.8 \pm 10.7$ & $43.7 \pm 10.6$ \\
\hline
\end{tabular}

Data are mean \pm SD

${ }^{*} \mathrm{p}<0.05$ compared to corresponding baseline value

\# $\mathrm{p}<0.05$ compared to corresponding placebo value musculoskeletal injury and reported no limitations to exercise. Subjects were informed of the experimental procedures and known risks, and signed an informed consent approved by the Ithaca College Human Subjects Review Board prior to participation.

\section{Experimental design}

This investigation examined the effects of two drink solutions on cycling sprint performance with a double blind cross-over design. The placebo was a commercial carbohydrate-electrolyte beverage (Wegmans MVP), whereas the same carbohydrate-electrolyte beverage with $2.5 \mathrm{~g}$ of betaine (minimum purity is $99 \%$; BetaPower ${ }^{\mathrm{TM}}$ DuPont Nutrition \& Health, Tarrytown, NY) was the experimental drink. Since betaine is colorless and tasteless, subjects could not differentiate between the two solutions. Furthermore, to ensure drink anonymity, all cap ties were broken prior to consumption. Subjects completed three cycling sprint tests, the first of which served as a baseline measure. Subjects were match-paired based upon maximum peak power and assigned to consume either the placebo or betaine beverage. They were instructed to consume approximately half $(295 \mathrm{~mL})$ of their respective beverage twice a day for seven days, after which they were tested again. The last drink was consumed the morning of the test day and all testing sessions took place in the evening. Following a three-week washout phase, a second seven day supplementation period with the opposite beverage occurred followed by the third testing session. Prior to every laboratory session, we used the Tanita 350 bioimedance body fat analyzer to assess the subjects' weight, total body water, fat free mass, and percent body fat (BF 350; Tanita Corporation of America, Inc. Arlington Heights, IL). This unit is valid and reliable [13-16].

\section{Performance testing}

Prior to every sprint test, subjects pedaled at a self-selected pace against a light resistance for $5 \mathrm{~min}$ to warm up with two to three interspersed sprints of short duration. The sprint test followed which consisted of four, $12 \mathrm{sec}$ work bouts on a Monark 834 E ergometer (Varberg, Sweden) against a resistance equal to $5.5 \%$ of body weight. Each work bout was separated by $2.5 \mathrm{~min}$ of cycling at zero resistance. At the completion of the test, subjects continued to pedal at zero resistance for $2.5 \mathrm{~min}$ to cool down. The ergometer was equipped with toe clips, seat height was standardized for each subject to allow for $10-15^{\circ}$ of knee flexion, and vigorous verbal encouragement was provided for all tests. SMI Power software (Sports Medicine Industries, St. Cloud, MN) interfaced with the ergometer with an OptoSensor 2000 infrared sensor (Sports Medicine Industries, St. Cloud, MN) collected data every second. The sensor was calibrated before every testing session. 
The following variables were measured during each sprint test: average peak power, maximum peak power, average mean power, and maximum mean power. Average peak and average mean power were calculated across the four work bouts in each sprint test; maximum peak and mean power were the highest values for the respective variables in any sprint test. Peak power was calculated as the highest power output over any five-second interval during a sprint test. The coefficient of variation for average peak power, maximum peak power, average mean power, and maximum mean power across two tests completed on separate days was assessed in a series of pilot studies $(n=6)$ and were $1.3,1.8,1.3$, and $1.6 \%$, respectively.

\section{Statistical analyses}

Data were analyzed using one-way repeated measures ANOVA. Where indicated, a Student Newman-Kuels test was used to identify specific differences (SigmaPlot v11, Systat Software Inc, San Jose, CA); alpha was set at 0.05 for all tests. Data are presented as mean \pm SD.

\section{Results}

Based on the mean and SD for maximum peak power from the pilot study and an a priori assumption that a $4 \%$ change in power pre- to post-supplementation is meaningful, we used GPOWER software (Bonn, FRG) to determine that a sample size of 14 was needed to give us a power of 0.80 with an alpha of 0.05 . Table 2 shows the mean and SD for average peak power, maximum peak power, average mean power and maximum mean power. Figures 1, 2, and 3 demonstrate mean and peak power across trials and gender. Compared to baseline, betaine ingestion increased average peak power $(6.4 \%$; $\mathrm{p}<0.001)$, maximum peak power $(5.7 \%$; $\mathrm{p}<0.001)$, average mean power $(5.4 \%$; $\mathrm{p}=0.004)$, and maximum mean power (4.4\%; $\mathrm{p}=0.004)$ for all subjects combined. Compared to placebo, betaine ingestion significantly increased average peak power $(3.4 \%$; $\mathrm{p}=0.026)$, maximum peak power $(3.8 \% ; \mathrm{p}=0.007)$, average mean power $(3.3 \% ; \mathrm{p}=0.034)$, and maximum mean power $(3.5 \% ; \mathrm{p}=0.011)$ for all subjects combined. There were no differences between the

Table 2 Combined power (watts) comparison for all subjects

\begin{tabular}{cccc}
\hline Variable & Baseline & Placebo & Betaine \\
\hline Peak Power & & & \\
Average & $608 \pm 140$ & $626 \pm 133$ & $647 \pm 144^{* \#}$ \\
Maximum & $644 \pm 144$ & $656 \pm 141$ & $681 \pm 145^{* \#}$ \\
Mean Power & & & \\
Average & $560 \pm 133$ & $571 \pm 126$ & $590 \pm 138^{* \#}$ \\
Maximum & $596 \pm 138$ & $601 \pm 131$ & $622 \pm 141^{* \#}$ \\
\hline
\end{tabular}

Data are mean \pm SD

* $p<0.05$ compared to corresponding baseline value

\# $\mathrm{p}<0.05$ compared to corresponding placebo value placebo and baseline trials. There were no differences across time or between conditions for any of the body composition variables.

\section{Discussion}

Our purpose was to examine the effect of one week of betaine ingestion on anaerobic power as measured with a series of four, $12 \mathrm{sec}$ work bouts. We found that one week of betaine ingestion $\left(2.5 \mathrm{gd}^{-1}\right)$ improved sprint performance by $5.5 \pm 0.8 \%$ compared to baseline and $3.5 \pm$ $0.2 \%$ compared to the carbohydrate placebo. These results contrast with data from Hoffman et al. [10], who reported daily consumption of 2.5 grams of betaine mixed with a commercially available carbohydrate beverage for 15 days did not enhance peak power, mean power, rate of fatigue, or total work across two Wingate trials separated by 5 min of active rest. One likely explanation for some of the difference in the results between the studies is the nature of the sprint test. Our subjects completed more sprints (4 vs. 2) of a shorter duration $(12 \mathrm{vs} .30 \mathrm{sec})$ that were interspersed with shorter periods of active recovery ( $2.5 \mathrm{vs} .5 \mathrm{~min}$ ) relative to the subjects in Hoffman et al. [10]. Experimental design may also account for some of the difference between the studies. Hoffman et al. [10] used a randomized repeated measures design, whereas we used a cross-over repeated measures design. Cross-over designs reduce the effects of confounding covariates and are more efficient statistically.

The likely mechanisms behind the increased power output we measured are related to methylation and osmolyte effects. Betaine supplementation may have elevated intramuscular creatine stores, increased muscle growth, or protected the muscle cells from stress-induced damage. The creatine hypothesis is attractive and supported by studies on betaine metabolism. In short, the liver enzyme betaine homocysteine methyltransferase transfers a methyl group from betaine to homocysteine, thereby producing dimethylglycine and methionine. The latter is then converted to $\mathrm{S}$-adenosylmethionine (SAM), which subsequently acts as a methyl donor during creatine synthesis [17]. Studies show that betaine ingestion increases serum methionine, while betaine injection increases red blood cell SAM concentrations $[18,19]$. Our observed changes in sprint performance, moreover, are consistent with the performance effects of creatine supplementation, as shown in a meta-analysis [20]. Across 100 studies, creatine supplementation improved performance parameters by $5.7 \pm$ $0.5 \%$ compared to baseline, whereas corresponding placebo effects were $2.4 \pm 0.4 \%$. More specifically, the metaanalysis showed that creatine supplementation improved lower extremity power by $5.6 \pm 0.6 \%$ relative to baseline, which is similar to the $5.5 \pm 0.8 \%$ increase we measured.

It is unlikely, however, that the amount of betaine consumed by our subjects $\left(2.5 \mathrm{~g}^{-1}\right.$ for $\left.7 \mathrm{~d}\right)$ elicits the same 


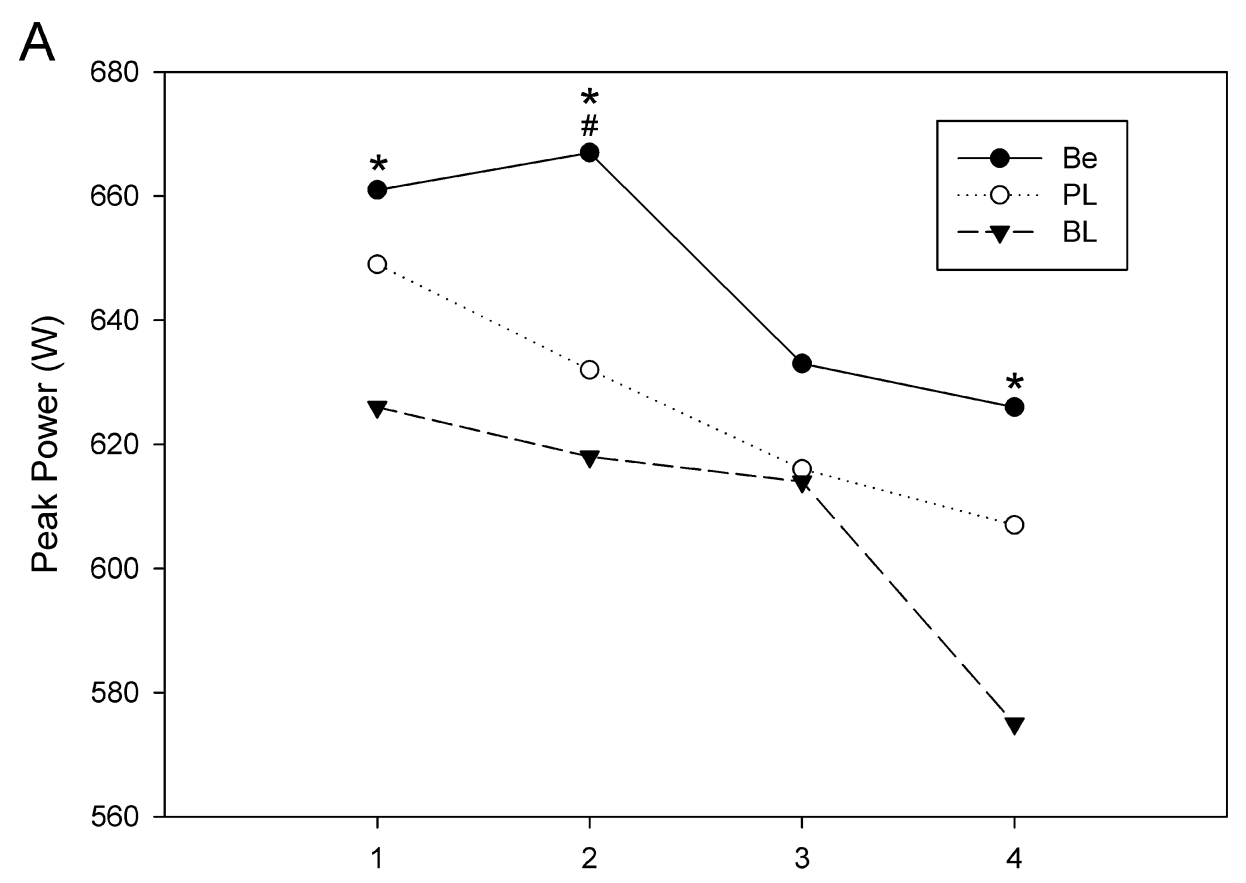

Work Bout

B

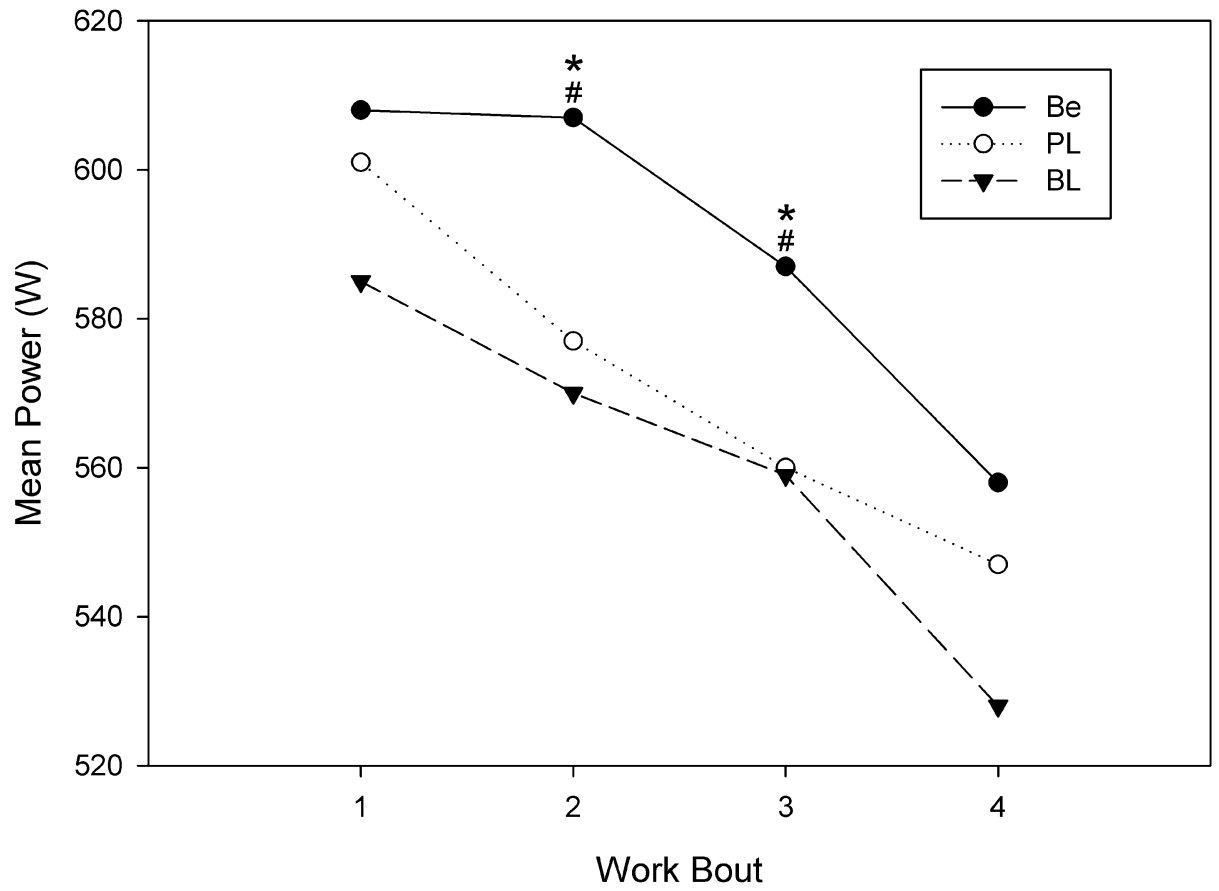

Figure 1 Individual cycle runs power comparison for all subjects. A: peak power; B: mean power. ${ }^{*} p<0.05$ compared to corresponding baseline value. ${ }^{\#} \mathrm{p}<0.05$ compared to corresponding placebo value. $\mathrm{W}=$ watts, $\mathrm{BL}=$ baseline, $\mathrm{PL}=$ placebo, $\mathrm{Be}=$ betaine.

effect as the typical daily dosage of creatine during the loading phase of approximately 25 grams. This conjecture is supported by recently published data showing that $2 \mathrm{~g}^{-1}$ of betaine for 10 day did not increase phosphorylcreatine levels compared to $20 \mathrm{gdd}^{-1}$ of creatine for 10 day [21]. This study also showed that betaine supplementation did not increase squat and bench press 1 RM or bench and squat power, findings that are 


\section{A}

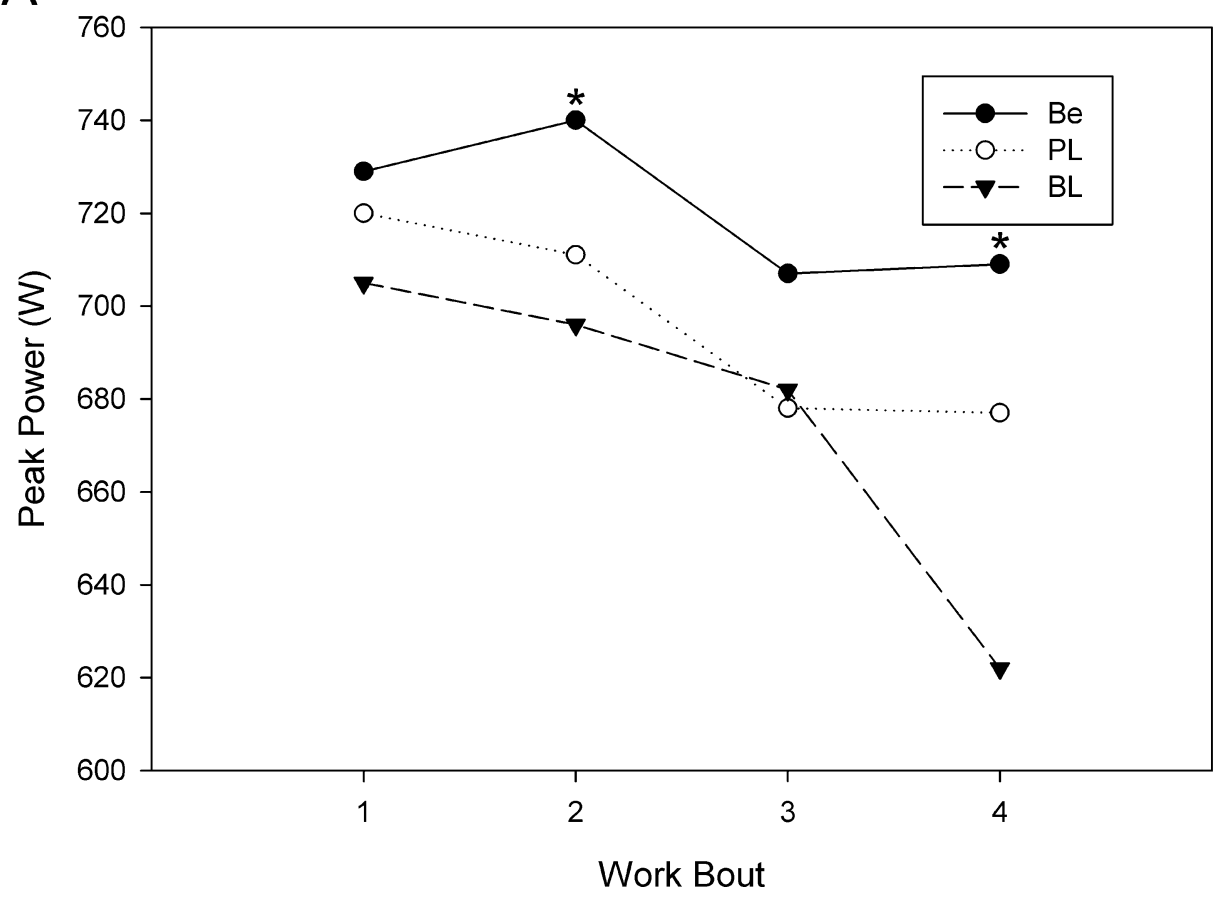

B

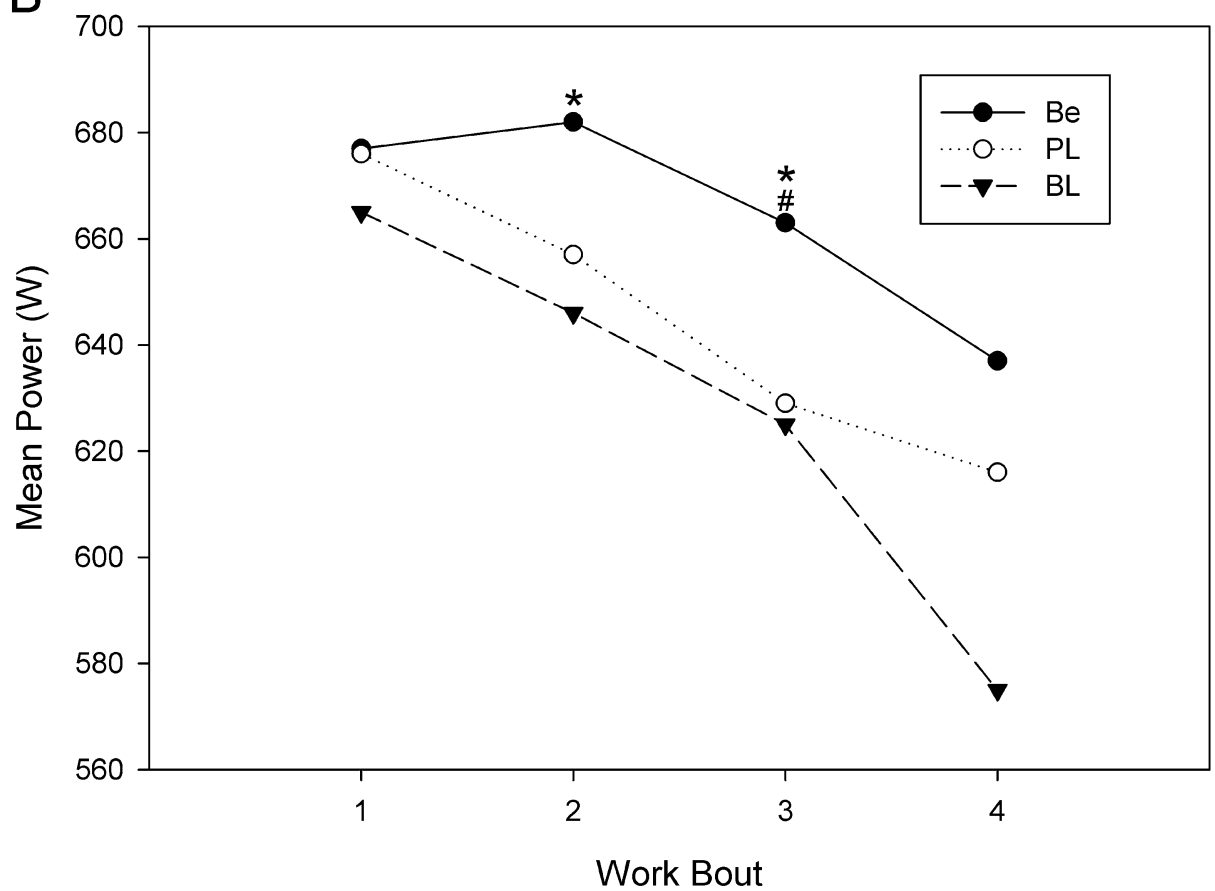

Figure 2 Individual cycle runs power comparison for males. A: peak power; B: mean power. ${ }^{*} p<0.05$ compared to corresponding baseline value. ${ }^{\#} \mathrm{p}<0.05$ compared to corresponding placebo value. $\mathrm{W}=$ watts, $\mathrm{BL}=$ baseline, $\mathrm{PL}=$ placebo, $\mathrm{Be}=$ betaine.

inconsistent with data from earlier studies [10-12]. Direct comparison among the studies is difficult. Betaine dosage was lower in the recent study ( $2 \mathrm{vs} 2.5 \mathrm{~g} \mathrm{~d}^{-1}$ ), supplementation time was shorter (10 vs $15 \mathrm{~d}$ ) and power output was not assessed until 3-5 d after supplementation ended compared to immediately afterwards $[10,11]$.

Last, betaine supplementation may have enhanced sprint performance by acting as an osmolyte to maintain 
A

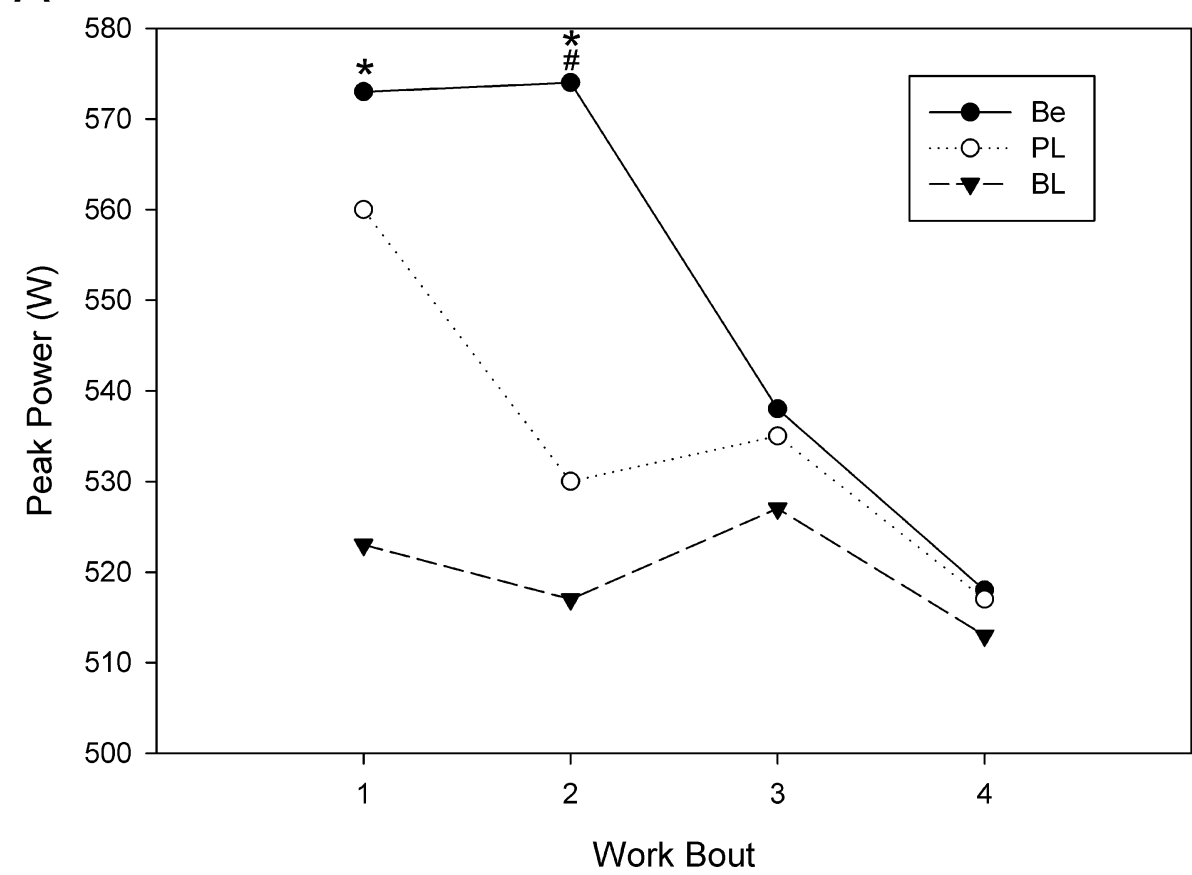

$\mathrm{B}$

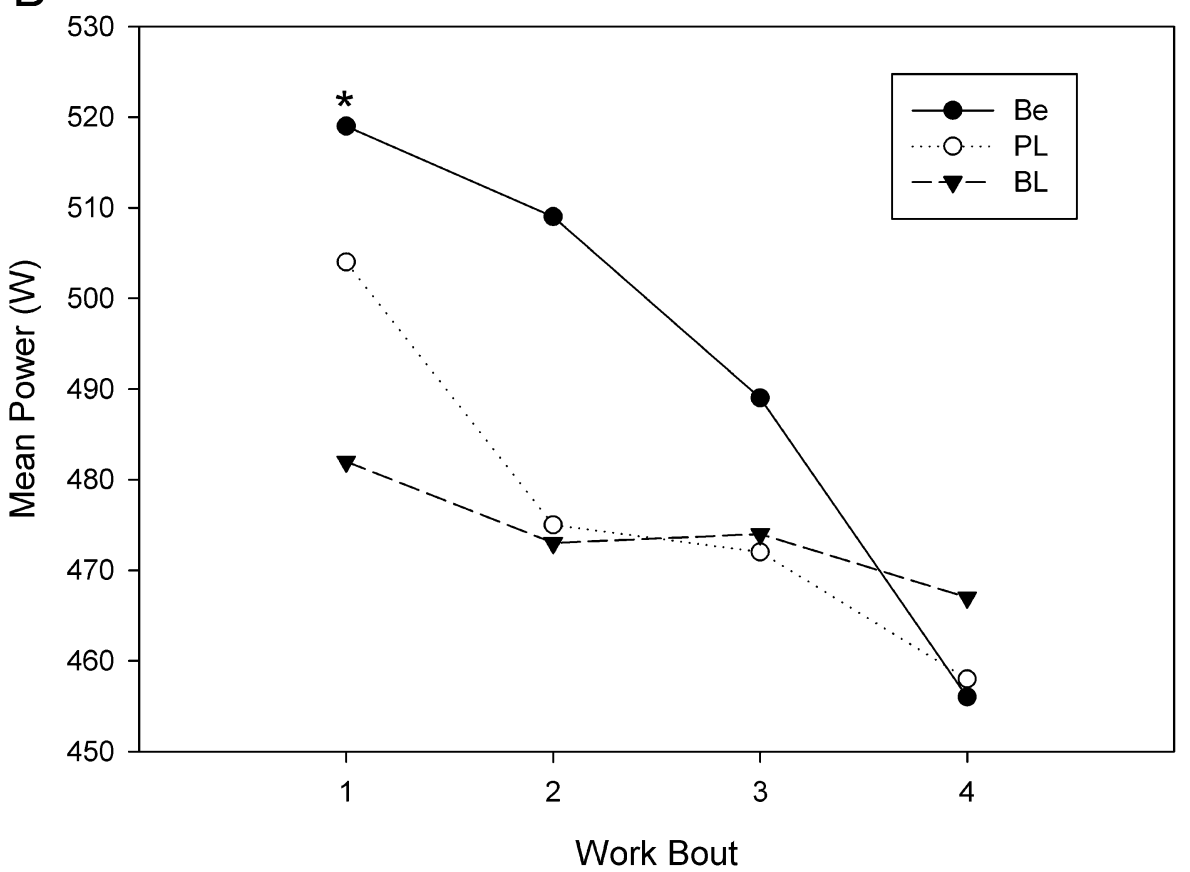

Figure 3 Individual cycle runs power comparison for females. A: peak power; B: mean power. ${ }^{*} p<0.05$ compared to corresponding baseline value. ${ }^{\#} \mathrm{p}<0.05$ compared to corresponding placebo value. $\mathrm{W}=$ watts, $\mathrm{BL}=$ baseline, $\mathrm{PL}=$ placebo, $\mathrm{Be}=$ betaine.

cell hydration and function under stress more effectively than placebo. Organic osmolytes are accumulated in cells when tissues are subjected to stress [6,22]. They help cells maintain optimal osmotic pressure, and allow proteins to maintain native folded conformation and stability without perturbing other cellular processes. Betaine helps maintain cell homeostasis by preventing formation of stress granules and keeping the mRNA 
associated machineries going under chronic hypertonicity [23]. Betaine is one of the most effective osmolytes, shown to facilitate a protective monolayer of water around biopolymers, enhance muscle cell survival and protein synthesis, and maintain myosin ATPase activity during periods of stress [24-26]. It may be that any or all of the aforementioned roles of betaine contributed to the $5.5 \%$ increase in power we observed.

\section{Conclusion}

We found that one week of betaine supplementation increased peak and mean anaerobic power by approximately 5.5\% compared to baseline measures in recreationally active college age men and women. The magnitude of this change is similar to the change in anaerobic power following creatine supplementation. Future research should elucidate the mechanism of improved performance via betaine supplementation.

\section{Acknowledgements}

DuPont Nutrition \& Health provided the BetaPower ${ }^{\mathrm{TM}}$ for the study. Authors would like to thank Michael Aoun for supplying the carbohydrate-electrolyte drink and Riana R. Pryor for her assistance with the study.

\section{Author details}

'Department of Kinesiology, University of Connecticut, Storrs, CT 06269, U1110, USA. ${ }^{2}$ DuPont Nutrition \& Health, Tarrytown, NY, USA. ${ }^{3}$ Ithaca College, Ithaca, NY, USA.

\section{Authors' contributions}

JLP participated in drafting, editing, and submitting the manuscript. SASC assisted with study design, statistical analysis and critically reviewed the manuscript for intellectual content. TS supervised the research group, ran the statistical analysis, interpreted data, and was involved with manuscript drafting. All authors read and approved the final manuscript.

\section{Competing interests}

JLP and TS declare that they have no competing interests and will not benefit from the results of the present study. SASC is an employee of DuPont Nutrition \& Health. Publication of these findings should not be viewed as endorsement by the investigators, Ithaca College, the University of Connecticut, or the editorial board of the Journal of the International Society of Sport Nutrition.

Received: 31 January 2012 Accepted: 3 April 2012

Published: 3 April 2012

\section{References}

1. Craig SAS: Betaine in human nutrition. Am J Clin Nutr 2004, 80:539-549

2. Zeisel SH, Mar MH, Howe JC, Holden JM: Concentrations of cholinecontaining compounds and betaine in common foods. J Nutr 2003, 133:1302-1307.

3. Konstantinova SV, Tell GS, Vollset SE, Nygard O, Bleie O, Ueland PM: Divergent associations of plasma choline and betaine with components of metabolic syndrome in middle age and elderly men and women. J Nutr 2008, 138:914-920.

4. Cho E, Willett WC, Colditz GA, Fuchs CS, Wu K, Chan AT, Zeisel SH, Giovannucci EL: Dietary choline and betaine and the risk of distal colorectal adenoma in women. J Natl Cancer Inst 2007, 99:1224-1231.

5. Shaw GM, Carmichael SL, Yang W, Selvin S, Schaffer DM: Periconceptional dietary intake of choline and betaine and neural tube defects in offspring. Am J Epidemiol 2004, 160:102-109.

6. Yancey PH, Clark ME, Hand SC, Bowlus RD, Somero GN: Living with water stress: evolution of osmolyte systems. Science 1982, 217:1214-1222.
7. Cronje P: Heat stress in livestock - role of the gut in its aetiology and a potential role for betaine in its alleviation. Recent Adv Anim Nutr Aust 2005, 15:107-122.

8. Armstrong LE, Casa DJ, Roti MW, Lee EC, Craig SAS, Sutherland JW, Fiala KA, Maresh CM: Influence of betaine consumption on strenuous running and sprinting in a hot environment. J Strength Cond Res 2008, 22:851-860.

9. Millard-Stafford M, Warren GL, Hitchcock KM, Welling RL, Rosskopf LB, Snow TK: Fluid replacement in the heat - effects of betaine. Med Sci Sports Exerc 2005, 37:S28.

10. Hoffman JR, Ratamess NA, Kang J, Rashti SL, Faigenbaum AD: Effect of betaine supplementation on power performance and fatigue. I Int Soc Sports Nutr 2009, 6:7-17.

11. Lee EL, Maresh CM, Kraemer WJ, Yamamoto LM, Hatfield DL, Bailey BL, Armstrong LE, Volek JS, McDermott BP, Craig SAS: Ergogenic effects of betaine supplementation on strength and power performance. J Int Soc Sports Nutr 2010, 7:27.

12. Trepanowski JF, Farney TM, MCCarthy CG, Schilling BK, Craig SA, Bloomer RJ: The effects of chronic betaine supplementation on exercise performance, skeletal muscle oxygen saturation, and associated biochemical parameters in resistance trained men. J Strength Cond Res 2011, 25:3461-3471.

13. Tyrrell VJ, Richards G, Hofman P, Gillies GF, Robinson E, Cutfield WS: Foot-tofoot bioelectrical impedance analysis: a valuable tool for the measurement of body composition in children. Int J Obes 2001, 25:273-278.

14. Utter AC, Nieman DC, Ward AN, Butterworth DE: Use of the leg-to-leg bioelectrical impedance method in assessing body composition change in obese women. Am J Clin Nutr 1999, 69:603-607.

15. Swartz AM, Evan MJ, King GA, Thompson DL: Evaluation of a foot-to-foot bioelectrical impedance analyser in highly active, moderately active and less active young men. Br J Nutr 2002, 88:205-210.

16. Parker L, Reilly JJ, Christine S, Wells JCK, Pitsiladis Y: Validity of six field and laboratory methods for measurement of body composition in boys. Obes Res 2003, 11:852-858.

17. du Vigneaud V, Simmonds S, Chandler JP, Cohn M: A further investigation of the role of betaine in transmethylation reactions in vivo. J Biol Chem 1946, 165:639-648.

18. Storch KJ, Wagner DA, Young VR: Methionine kinetics in adult men: effects of dietary betaine on L-[2H3-methyl-1-13C]methionine. Am J Clin Nutr 1991, 54:386-394.

19. Wise CK, Cooney CA, Ali SF, Poirier LA: Measuring S-adenosylmethionine in whole blood, red blood cells and cultured cells using a fast preparation method and high-performance liquid chromatography. J Chromatogr B Biomed Sci Appl 1997, 696:145-152.

20. Branch JD: Effect of creatine supplementation on body composition and performance: a meta-analysis. Int J Sport Nutr Exerc Metab 2003, 13:198-226.

21. Del Favero S, Roschel H, Artioli G, Ugrinowitsch C, Tricoli V, Costa A, Barroso R, Negrelli AL, Otaduy MC, da Costa Leite C, Lancha-Junior AH, Gualano B: Creatine but not betaine supplementation increases muscle phosphorylcreatine content and strength performance. Amino Acids 2011, doi: 10.1007/s00726-011-0972-5.

22. Kumar R: Role of naturally occurring osmolytes in protein folding and stability. Arch Biochem Biophys 2009, 491:1-6.

23. Bounedjah O, Hamon L, Savarin P, Desdorges B, Curmi PA, Pastre D: Macromolecular crowding regulates the assembly of mRNA stress granules after osmotic stress: a new role for compatible osmolytes. J Biol Chem 2011, doi: 10.1074/jbc.M111.292748 jbc.M111.292748.

24. Ueland PM: Choline and betaine in health and disease. J Inherit Metab Dis 2011, 34:3-15.

25. Kraemer WJ, Bailey BL, Clark JE, Apicella J, Lee EC, Comstock BE, DunnLewis C, Volek J, Kupchak B, Anderson JM, Craig SAS, Mares CM: The influence of betaine supplementation on work performance and endocrine function in men [abstract]. J Strength Cond Res 2011, 25: s100-s101.

26. Brigotti M, Petronini P, Carnicelli D, Alfieri R, Bonelli M, Borghetti A, Wheeler K: Effects of osmolarity, ions and compatible osmolytes on cellfree protein synthesis. Biochem J 2003, 369:369-374.

doi:10.1186/1550-2783-9-12

Cite this article as: Pryor et al:: Effect of betaine supplementation on cycling sprint performance. Journal of the International Society of Sports Nutrition 2012 9:12. 